\title{
LEFT ATRIAL FUNCTION ASSESSMENT BY 2D- SPECKLE TRACKING ECHOCARDIOGRAPHY IN HEMODIALYSIS PATIENTS WITH NORMAL LEFT VENTRICULAR SYSTOLIC FUNCTION
}

\author{
By
}

\author{
Ahmed Kahil, Ahmed Al-Habbaa and Sameh Allam \\ Department of Cardiology, Faculty of Medicine, Al-Azhar University, Egypt \\ Corresponding author: Ahmed Ali Kahil, Department of Cardiology, Mahalla \\ Cardiology Center, Mahalla, Egypt
}

Tel.: +201023945963, E-mail: dr_kaheeel@yahoo.com

\begin{abstract}
Background: Chronic renal failure leads to structural changes and functional abnormalities in the heart, which are known as uremic cardiomyopathy. These changes may be progressive and related directly to a grossly aggravated risk of cardiovascular events. Left atrial volume estimated by echocardiography is reported to be a sensitive marker of LV diastolic dysfunction and LA function plays a central role in maintaining optimal cardiac output despite impaired LV relaxation and reduced LV compliance.
\end{abstract}

Objective: The aim of the study was to investigate the regional function of the left atrial myocardium using two-dimensional speckle tracking echocardiography in hemodialysis patients with preserved left ventricular ejection fraction.

Patients and methods: This study was a cross-sectional comparative study conducted on 80 individuals divided into two groups; Group (1) (the control group) consisted of 20 healthy individuals, Group (2) consisted of 60 patients on regular hemodialysis.

All patients were subjected to full history taking, complete physical examination, resting 12-lead electrocardiography, left ventricular assessment by conventional echocardiography and speckle tracking echocardiography, left atrial assessment by conventional echocardiography and speckle tracking echocardiography.

Results: In our study, the left atrial global longitudinal strain (LAGLS) value assessed by speckle tracking echocardiography significantly decreased in group (1) which was $34.63 \pm 10.78$ versus $46.76 \pm 8.99$ in group (2).

Conclusion: The mean left atrial global longitudinal strain (LAGLS) significantly decreased in patients with ESRD on regular hemodialysis.

Key words: End-stage renal disease, speckle tracking echocardiography, left atrial strain.

\section{INTRODUCTION}

Echocardiography is noninvasive cardiac imaging that is widely available and provides invaluable information on cardiac morphology and function. Speckle-tracking echocardiography is a noninvasive ultrasound imaging technique that allows for an objective and quantitative evaluation of global and regional myocardial function independently from the angle of 
insonation and from cardiac translational movements (Geyer et al., 2010).

Speckle-tracking echocardiography is based on an analysis of the spatial dislocation (referred to as tracking) of speckles (defined as spots generated by the interaction between the ultrasound beam and myocardial fibers) on routine 2dimensional sonograms (Götte et al., 2006).

The developed two-dimensional speckle-tracking echocardiography (2DSTE) method has enabled a simple and angle-independent evaluation of the left ventricle (LV) deformation in the longitudinal, radial, and circumferential directions. 2D-STE is more sensitive than conventional echocardiography in detecting subclinical ventricular dysfunction in various clinical disorders (Altekin et al., 2014).

Chronic renal failure leads to structural changes and functional abnormalities in the heart, which are known as uremic cardiomyopathy. These changes may be progressive and related directly to a grossly aggravated risk of cardiovascular (CV) events and reduced survival rates (Dohi, 2019).

The LAV predicts mortality aside from left ventricular (LV) hypertrophy and LV dysfunction, or the other risk factors in ESRD patients. Monitoring the LAV provides prognostic information beyond the echocardiographic markers of high $\mathrm{CV}$ risk (Latif et al., 2019).

Because the LA is directly exposed to LV diastolic pressure through the mitral valve, the size of the LA reflects the duration and severity of increased LA pressure following increased LV diastolic pressure. Therefore, LAV is reported to be a sensitive marker of $\mathrm{LV}$ diastolic dysfunction (Thomas et al., 2019).

LA function plays a central role in maintaining optimal cardiac output despite impaired LV relaxation and reduced LV compliance (Meijs et al., 2018).

Echocardiographic studies conducted on different patient groups have demonstrated that the phasic functions of LA diminish in parallel to the increase in the LAV. Especially in heart failure patients with preserved LV ejection fraction (PLVEF), the reduction in the LA function may lead to a decrease in the functional capacity and to $\mathrm{CV}$ complications (Altekin et al., 2013).

The aim of our study was to investigate the regional function of the left atrial (LA) myocardium using two-dimensional speckle tracking echocardiography (2DSTE) in hemodialysis patients with preserved left ventricular ejection fraction.

\section{PATIENTS AND METHODS}

This cross-sectional comparative study was carried out at Cardiology Department at "Bab El-She'ryia University Hospital" during the period from May 2018 to September 2019. This study included 80 individuals between the ages of 18-60 divided into two groups; Group (1) consisted of 20 healthy individuals (The control group) and group (2) consisted of 60 patients on regular hemodialysis. All patients gave informed consent to participate in the study.

The exclusion criteria included patient's refusal, coronary artery disease based on patient history, physical examination, electrocardiography, 
echocardiography, significant Valvular heart disease (valvular lesion more than mild), diabetes mellitus (fasting plasma glucose concentration $\geq 126 \mathrm{mg} / \mathrm{dL}$, glycosylated hemoglobin $>6.5 \%$, or use of hypoglycemic medication), New York Heart Association class III-IV heart failure, Rhythms other than sinus rhythm and liver disease that might disrupt cardiac structure or function.

\section{All patients were subjected to:}

\section{- Complete history taking.}

- Physical Examination.

- Electrocardiography.

- Transthoracic Echo Doppler study.

- Left ventricular assessment: Images were obtained from the parasternal and apical positions using 2D, M-mode and Doppler echocardiographic examinations according to the guidelines of the American Society of Echocardiography for the evaluation of LV structures, the systolic and diastolic functions, and calculation of the values dependent on these functions. The LV mass was calculated according to the anatomically validated Devereux formula and indexed by the BSA (Altekin et al., 2014a). The LVEF was measured using the biplane Simpson's method from apical four- and twochamber views. Tissue Doppler images (TDI) were recorded from the apical four-chamber view using the pulsedwave Doppler with a $3 \mathrm{~mm}$ sample volume placed on the septal and lateral mitral annulus. All the annular velocities and time intervals of tissue Doppler analyses were calculated as the average of the two annular sites. Pulsed wave TDI examinations were performed according to the guidelines of the American Society of Echocardiography (Porter et al., 2015). The ratio of the mitral early diastolic flow velocity (E) and the mitral annular early diastolic myocardial velocity (E') were calculated.

- Left atrial assessment: From the apical four- and two-chamber views, LAV was calculated using the arealength method according to the guidelines of the American Society of Echocardiography (Plana et al., 2014). For the LA 2D-STE analysis, images from the apical four and two-chamber views were obtained using conventional 2D grey scale echocardiography while holding the breath and simultaneously taking an electrocardiography reading (Mochizuki et al., 2013). Patients in whom ECG gating was not accurate or not present were excluded. All images were obtained at a frame rate of $60-80$ frames/s. Three consecutive heart cycles were recorded in digital format for offline analysis.

In order to calculate the LAS, the atrial endocardium was first manually traced in end-systolic frame. The epi-cardial surface is calculated automatically, and after manually reducing the region of interest to the atrial thickness, the software automatically divides the atrial wall into six segments. Before acquiring the LAS view from the apical four- and two-chambers if speckle tracking is not adequate, the region of interest is manually adjusted to include only the atrial wall. Segments in which adequate tracking quality could not be obtained despite manual adjustments were excluded 
from the analysis. Patients in whom no adequate tracking quality was obtained in more than two segments were also excluded from the study. Finally, the software calculated the average LAS for six segments for each apical view and the LAS values for each view were calculated from the averages of the values obtained from the LA segments in each view. The final LAS values were the averages of the values obtained for each apical view.

\section{Statistical analysis:}

Data were analyzed using Statistical Program for Social Science (SPSS) version 25.0 for windows. Quantitative data were expressed as mean \pm standard deviation (SD). Qualitative data were expressed as frequency and percentage.

Comparisons between the groups were performed with Independent-samples ttest of significance was used when comparing between two means of normally distributed data, Chi-square (X2) test was used to discover if there was a relationship between two categorical variables and Fisher Exact test was a test of significance that was used in the place of Chi square test especially in cases of small samples. Pearson's coefficients were calculated to assess relationship between study parameters. P-value $<0.05$ was considered significant.

\section{RESULTS}

The study enrolled 80 participants divided into two groups; group I consisted of 20 healthy individuals (The control group) and group II enrolled 60 patients on chronic hemodialysis with preserved left ventricular ejection fraction.

Demographic data of the studied groups:
1. Age: The mean age of the study population was 35.3 years $\pm 12.7 \mathrm{SD}$. In group I the mean was 29.5years \pm 10.5 SD, in group II, the mean was 37.3 years \pm 13.2 SD. The main difference between the two groups was statistically significant, $\mathrm{P}$ value $=0.019$ (Table 1).

Table (1): Comparison between the studied groups regarding the baseline characteristics

\begin{tabular}{|l|c|c|c|}
\hline $\begin{array}{l}\text { Baseline Groups } \\
\text { characteristics }\end{array}$ & Control group & FR group & \multirow{2}{*}{ P-value } \\
\hline Count & 20 & 60 & \\
\hline Age (years) & $29.5 \pm 10.5$ & $37.3 \pm 13.2$ & 0.019 \\
\hline Weight (kg) & $69.0 \pm 15.8$ & $76.7 \pm 17.3$ & 0.080 \\
\hline Height (cm) & $163.3 \pm 10.1$ & $164.1 \pm 9.3$ & 0.736 \\
\hline Demographics & $7(35 \%)$ & $20(33.3 \%)$ & 0.891 \\
\hline Male gender & $5(25 \%)$ & $19(31.7 \%)$ & 0.573 \\
\hline Hypertension & $3(15 \%)$ & $3(5 \%)$ & 0.162 \\
\hline Smoking
\end{tabular}

2. Body weight: The mean weight of the study population was $74.8 \mathrm{~kg} \pm 17.2$
SD. In group I, the mean was $69.0 \mathrm{~kg} \pm$ 15.8 SD, in group II, the mean was 
$76.7 \mathrm{~kg} \pm 17.3 \mathrm{SD}$. There was no statistical significance between the two groups, $\mathrm{P}$ value $=0.080$ (Table 1) .

3. Height: The mean height of the study population was $163.9 \mathrm{~cm} \pm 6.5 \mathrm{SD}$. In group I, the mean was $163.3 \mathrm{~cm} \pm 10.1$ $\mathrm{SD}$, in group II, the mean was 164.1 $\mathrm{cm} \pm 9.3 \mathrm{SD}$. There was no statistical significance between the two groups, $\mathrm{P}$ value $=0.736$ (Table 1$)$.

4. Gender: There were 27 males $(33.8 \%)$ and 53 females $(66.2 \%)$ in the whole study population. In group I there were 7 males $(35 \%)$ and 13 females $(65 \%)$, in group II there were 20 males $(33.3 \%)$ and 40 females (66.7 \%). There was no statistically significant difference between the two groups, $\mathrm{P}$ value $=0.891$ ( Table 1).

The cardiovascular risk factors in each group:

1. Hypertension: There were 24 hypertensive patients $(30 \%)$ in whole study population. In group I there were 5 patients hypertensive $(25 \%)$ while in group II, there were 19 patients hypertensive (31.7\%). There was no statistically significant difference between the two groups, $\mathrm{P}$ value = 0.573 (Table 1).

2. Smoking: There were 6 patients smoking $(7.5 \%)$ in whole study population. In group I, there were 3 patients smoking (5\%) and in group II there were 3 patients smoking (15\%). There was no statistically significant difference between the two groups, $\mathrm{P}$ value $=0.162$ (Table 1).

Conventional Echocardiographic data findings of the studied groups

A. LV dimensions of the studied groups:

1. Left ventricular internal diameter in diastole (LVIDd): The mean LVIDd of the study population was $4.80 \mathrm{~cm} \pm$ $0.65 \mathrm{SD}$. In group I the mean was 4.41 $\mathrm{cm} \pm 0.71 \mathrm{SD}$, in group II the mean was $4.94 \mathrm{~cm} \pm 0.59 \mathrm{SD}$. There was statistical significance between the two groups, $\mathrm{P}$ value $=0.001$ (Table 2) .

2. Left ventricular internal diameter in systole (LVIDs): The mean LVIDs of the study population were $3.00 \mathrm{~cm} \pm$ $0.5 \mathrm{SD}$. In group I the mean was $2.82 \pm$ $0.54 \mathrm{SD}$, in group II the mean was 3.07 $\mathrm{cm} \pm 0.47 \mathrm{SD}$. There was no statistical significance between the two groups, $\mathrm{P}$ value $=0.052$ (Table 2) .

3. Left ventricular posterior wall diameter in diastole (LVPWd): The mean LVPWd of the study population was $0.77 \pm 0.21 \mathrm{SD}$. In group I the mean was $0.71 \mathrm{~cm} \pm 0.20 \mathrm{SD}$, in group II the mean was $0.80 \mathrm{~cm} \pm 0.21 \mathrm{SD}$. There was no statistical significance between the two groups, $\mathrm{P}$ value $=0.121$ (Table 2).

4. Interventricular septum in diastole (IVSd): The mean IVSd of the study population was $0.75 \mathrm{~cm} \pm 0.21 \mathrm{SD}$. In group I the mean was $0.74 \mathrm{~cm} \pm 0.15$ $\mathrm{SD}$, in group II the mean was $0.75 \mathrm{~cm}$ $\pm 0.22 \mathrm{SD}$. There was no statistical significance between the two groups, $\mathrm{P}$ value $=0.869$ (Table 2 )

B) LV functions of the studied groups:

1. Left ventricular fractional shortening (FS): The mean FS of the study population was $37.4 \mathrm{~cm} \pm 5.4 \mathrm{SD}$. In group I the mean was $36.7 \% \pm 5.8 \mathrm{SD}$, in group II the mean was $37.6 \% \pm 5.3$ SD. There was no statistical significance between the two groups, $\mathrm{P}$ value $=0.487$ (Table 2 ) .

2. Left ventricular ejection fraction $(\mathrm{EF})$ : The mean EF of the study population was $65.4 \% \pm 6.1 \mathrm{SD}$. In group I the mean was $67.1 \% \pm 6.6 \mathrm{SD}$, in group II the mean was $64.8 \% \pm 5.9 \mathrm{SD}$. There was no statistical significance between the two groups, $\mathrm{P}$ value $=0.143$ (Table 2). 
AHMED KAHIL et al.,

Table (2): LV and aortic parameters

\begin{tabular}{|l|c|c|c|c|}
\hline $\begin{array}{l}\text { LV and Groups } \\
\text { Aortic parameters }\end{array}$ & $\begin{array}{c}\text { All patients } \\
(80)\end{array}$ & $\begin{array}{c}\text { Control } \\
\text { group(20) }\end{array}$ & $\begin{array}{c}\text { FR group } \\
\text { (60) }\end{array}$ & P-value \\
\hline LV dimensions & \multicolumn{4}{|l|}{} \\
\hline LVIDd (cm) & $4.80 \pm 0.65$ & $4.41 \pm 0.71$ & $4.94 \pm 0.59$ & 0.001 \\
\hline LVIDs (cm) & $3.00 \pm 0.50$ & $2.82 \pm 0.54$ & $3.07 \pm 0.47$ & 0.052 \\
\hline LVPWd (cm) & $0.77 \pm 0.21$ & $0.71 \pm 0.20$ & $0.80 \pm 0.21$ & 0.121 \\
\hline IVSd (cm) & $0.75 \pm 0.21$ & $0.74 \pm 0.15$ & $0.75 \pm 0.22$ & 0.869 \\
\hline LV functions & $37.4 \pm 5.4$ & $36.7 \pm 5.8$ & $37.6 \pm 5.3$ & 0.525 \\
\hline FS (\%) & $65.4 \pm 6.1$ & $67.1 \pm 6.6$ & $64.8 \pm 5.9$ & 0.187 \\
\hline EF (\%) & \multicolumn{4}{|l|}{} \\
\hline LV volumes & $110.3 \pm 30.9$ & $106.8 \pm 25.8$ & $111.5 \pm 32.5$ & 0.560 \\
\hline LVEDV4C (mL) & $44.2 \pm 15.2$ & $44.3 \pm 12.2$ & $44.2 \pm 16.2$ & 0.982 \\
\hline LVESV4C (mL) & $109.0 \pm 34.9$ & $112.2 \pm 32.5$ & $108.0 \pm 35.9$ & 0.641 \\
\hline LVEDV2C (mL) & $41.9 \pm 16.4$ & $45.3 \pm 17.1$ & $40.8 \pm 16.2$ & 0.287 \\
\hline LVESV2C (mL) & $7.92 \pm 2.37$ & $7.87 \pm 2.45$ & $7.94 \pm 2.37$ & 0.912 \\
\hline TDI parameters & \multicolumn{4}{|l|}{} \\
\hline E/E & $2.85 \pm 0.47$ & $2.83 \pm 0.41$ & $2.65 \pm 0.47$ & 0.131 \\
\hline Aortic parameters & $\begin{array}{l}\text { Aortic root } \\
\text { dimensions }\end{array}$ &
\end{tabular}

\section{LV volumes of the studied groups:}

1. Left ventricular end diastolic volume in apical 4 chambers view (LVEDV4C): The mean LVEDV4C of the study population was $110.3 \mathrm{ml} \pm 30.9 \mathrm{SD}$. In group I the mean was $106.8 \mathrm{ml} \pm 25.8$ $\mathrm{SD}$, in group II the mean was $111.5 \mathrm{ml}$ \pm 32.5 SD. There was no statistical significance between the two groups, $\mathrm{P}$ value $=0.560$ (Table 2).

2. Left ventricular end systolic volume in apical 4 chambers view (LVESV4C): The mean LVESV4C of the study population was $44.2 \mathrm{ml} \pm 15.2 \mathrm{SD}$. In group I the mean was $44.3 \mathrm{ml} \pm 12.2$ $\mathrm{SD}$, in group II the mean was $44.2 \mathrm{ml} \pm$ 16.2 SD. There was no statistical significance between the two groups, $\mathrm{P}$ value $=0.982$ (Table 2 )

3. Left ventricular end diastolic volume in apical 2 chambers view (LVEDV2C): The mean LVEDV2C of the study population was $109 \mathrm{ml} \pm 34.9 \mathrm{SD}$. In group I the mean was $112.2 \mathrm{ml} \pm 32.5$ $\mathrm{SD}$, in group II the mean was $108 \mathrm{ml} \pm$
35.9 SD. There was no statistical significance between the two groups, $\mathrm{P}$ value $=0.641$ (Table 2) .

4. Left ventricular end systolic volume in apical 2 chambers view (LVESV2C): The mean LVESV2C of the study population was $41.9 \mathrm{ml} \pm 16.4 \mathrm{SD}$. In group I the mean was $45.3 \mathrm{ml} \pm 17.1$ $\mathrm{SD}$, in group II the mean was $40.8 \mathrm{ml} \pm$ 16.2 SD. There was no statistical significance between the two groups, $\mathrm{P}$ value $=0.287$ (Table 2 ) .

D. Tissue doppler imaging for assessment of diastolic dysfunction of left ventricle ( $\left.E / E^{\prime}\right)$ :

The mean value of E/E': The mean value of $E / E$ ' of the study population was $7.92 \pm 2.37 \mathrm{SD}$. In group I the mean was $7.87 \pm 2.45 \mathrm{SD}$, in group II the mean was $7.94 \pm 2.37$ SD. There was no statistical significance between the two groups, $\mathrm{P}$ value $=0.912$ (Table 2) .

\section{E. Aortic parameters:}

Aortic root dimension: The mean Aortic root dimension of the study 
population was $2.85 \mathrm{~cm} \pm 0.47 \mathrm{SD}$. In group I the mean was $2.83 \mathrm{~cm} \pm 0.41 \mathrm{SD}$, in group II the mean was $2.65 \mathrm{~cm} \pm 0.47$ SD. There was statistical significance between the two groups, $\mathrm{P}$ value $=0.023$ (Table 2).

F. Left atrial dimensions and volumes of the studied groups:

1. Left atrial diameter (LAD): In group I the mean was $3.22 \mathrm{~cm} \pm 0.50 \mathrm{SD}$, in group II the mean was $3.44 \mathrm{~cm} \pm 0.51$ SD. There was no statistical significance between the two groups, $\mathrm{P}$ value $=0.099$ (Table 3)

2. Left atrial volume (LAV): In group I the mean was $36.7 \mathrm{ml} \pm 14.3 \mathrm{SD}$, in group II the mean was $44.7 \mathrm{ml} \pm 15.5$ SD. There was statistical significance between the two groups, $\mathrm{P}$ value = 0.044 (Table 3).

3. Left atrial indexed volume (LAIV): In group I the mean was $21.3 \mathrm{~mL} / \mathrm{m} 2 \pm$ 5.5 SD, in group II the mean was 24.5 $\mathrm{mL} / \mathrm{m} 2 \pm 7.9$ SD. There was no statistical significance between the two groups, $\mathrm{P}$ value $=0.096($ Table 3$)$.
G. Left atrial speckle tracking echocardiography of the studied groups (Global longitudinal strain):

1. Left atrial global longitudinal strain in apical 4 chambers view (LAA4C): In group I the mean was $51.78 \% \pm$ $12.11 \mathrm{SD}$, in group II the mean was $38.61 \% \pm 12.42$ SD. There was statistical high significance between the two groups, $\mathrm{P}$ value $<0.001$ (Table 3) and (Figure 1).

2. Left atrial global longitudinal strain in apical 2 chambers view (LAA2C GLS): In group I the mean was 41.74 $\% \pm 9.88 \mathrm{SD}$, in group II the mean was $31.36 \% \pm 13.32$ SD. There was statistical significance between the two groups, $\mathrm{P}$ value $=0.002$ (Table 3 ) and (Figure 1).

3. The mean left atrial global longitudinal strain (mean LA GLS): In group I the mean was $46.76 \% \pm 8.99 \mathrm{SD}$, in group II the mean was $34.63 \% \pm 10.78$ SD. There was statistical high significance between the two groups, $\mathrm{P}$ value $<0.001$ (Table 3 and Figure 1).

Table (3): Comparison between the studied groups regarding the LA parameters

\begin{tabular}{|l|c|c|c|}
\hline LA parameters & $\begin{array}{c}\text { Control } \\
\text { group (20) }\end{array}$ & FR group (60) & P-value \\
\hline LA dimensions and volumes \\
\hline LAD $(\mathrm{cm})$ & $3.22 \pm 0.50$ & $3.44 \pm 0.51$ & 0.099 \\
\hline LAV $(\mathrm{mL})$ & $36.7 \pm 14.3$ & $44.7 \pm 15.5$ & 0.044 \\
\hline LAVI (mL/m $\left.{ }^{2}\right)$ & $21.3 \pm 5.5$ & $24.5 \pm 7.9$ & 0.096 \\
\hline LA speckle tracking & $51.78 \pm 12.11$ & $38.61 \pm 12.42$ & $<0.001$ \\
\hline LAA4C GLS (\%) & $41.74 \pm 9.88$ & $31.36 \pm 13.32$ & 0.002 \\
\hline LAA2C GLS (\%) & $46.76 \pm 8.99$ & $34.63 \pm 10.78$ & $<0.001$ \\
\hline Mean LA GLS (\%)
\end{tabular}




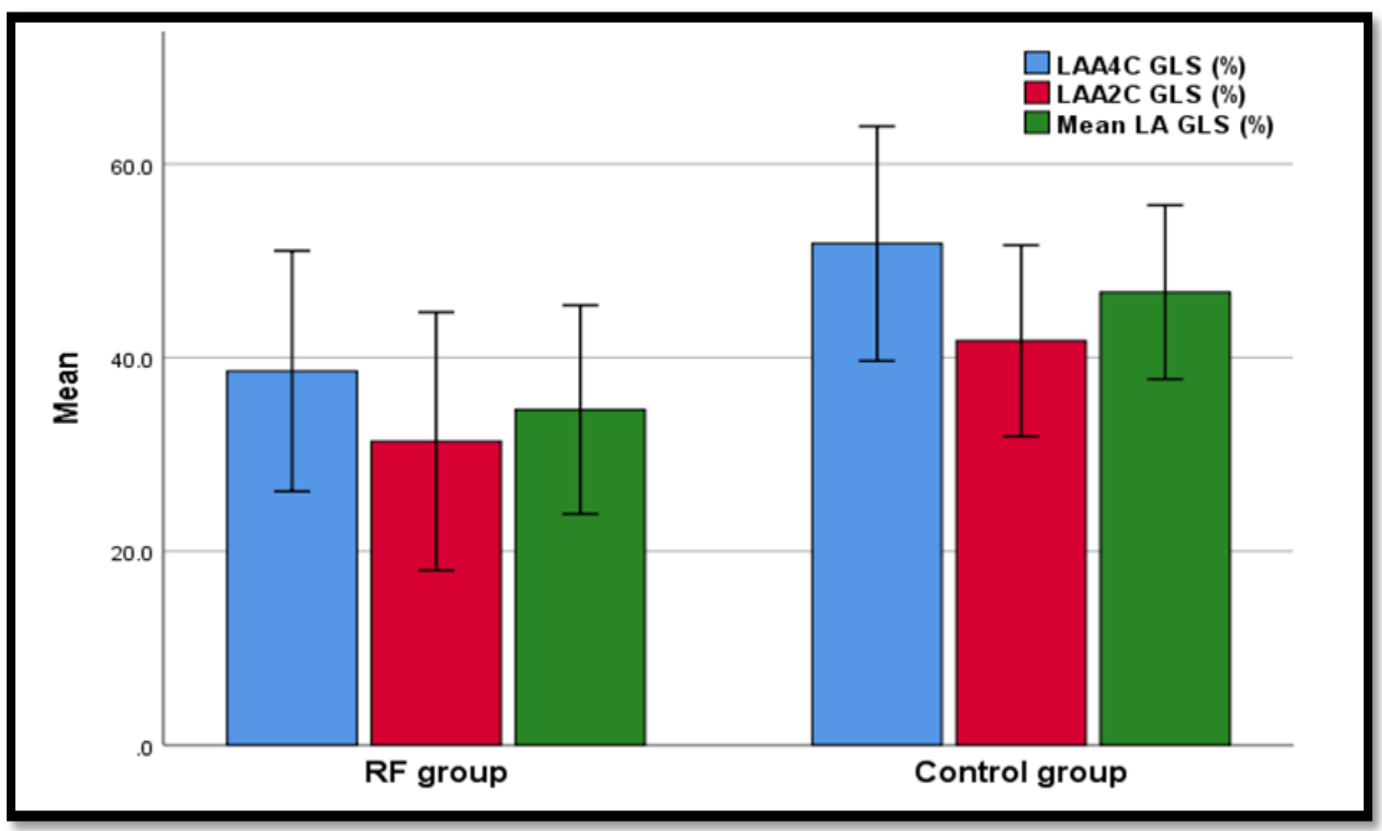

Figure (1): Comparison between both groups regarding LA speckle tracking.

Correlation analysis between mean LA GLS (\%) and other variables:

1. Age: There was a statistically significant negative correlation with the mean LA GLS with P value < 0.001, $\mathrm{r}$ value $=-0.412$ (Table 4 and Figure2).

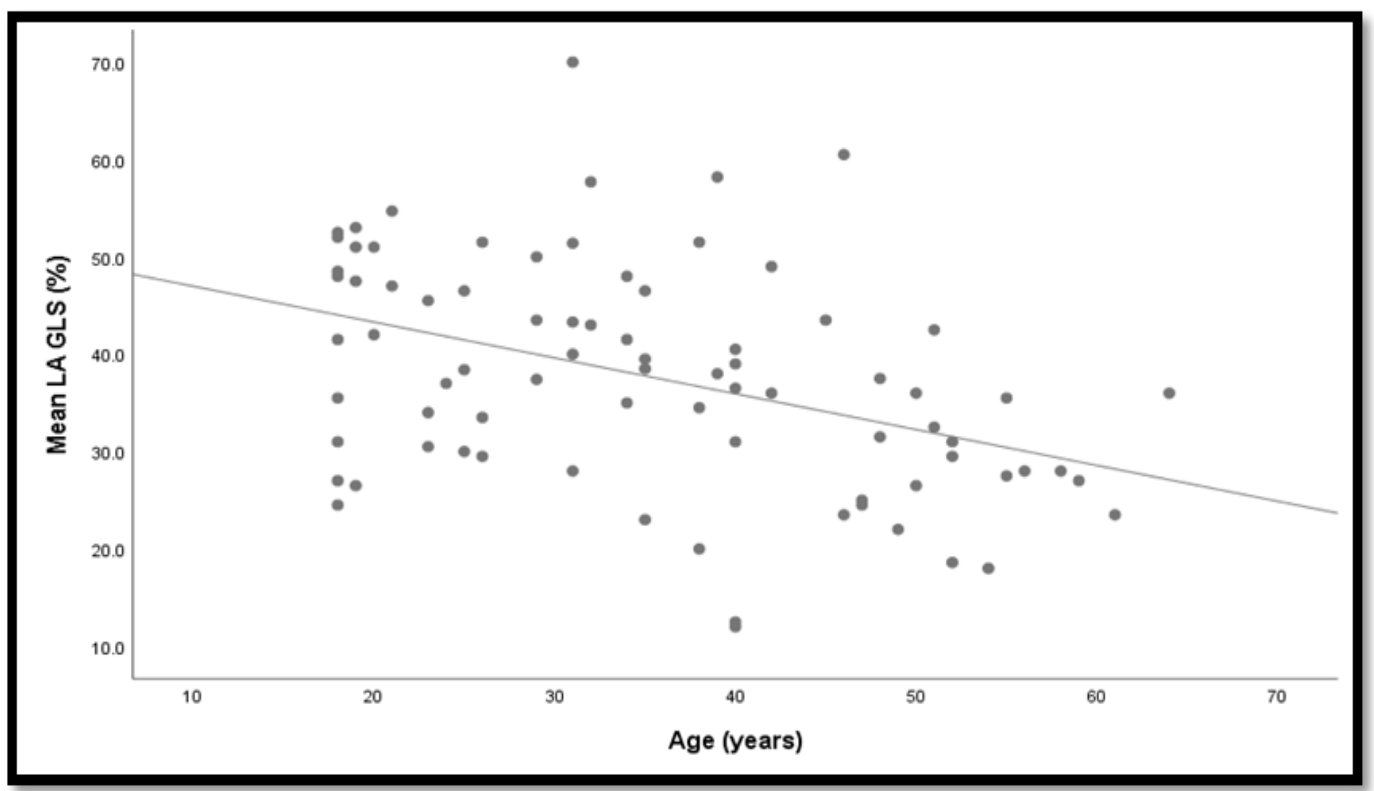

Figure (2): Correlation analysis between mean LA GLS (\%) and age.

2. Weight: There was a statistically significant negative correlation with the mean LA GLS with $\mathrm{P}$ value $=0.020, \mathrm{r}$ value $=-0.260$ (Table 4 and Figure 3). 


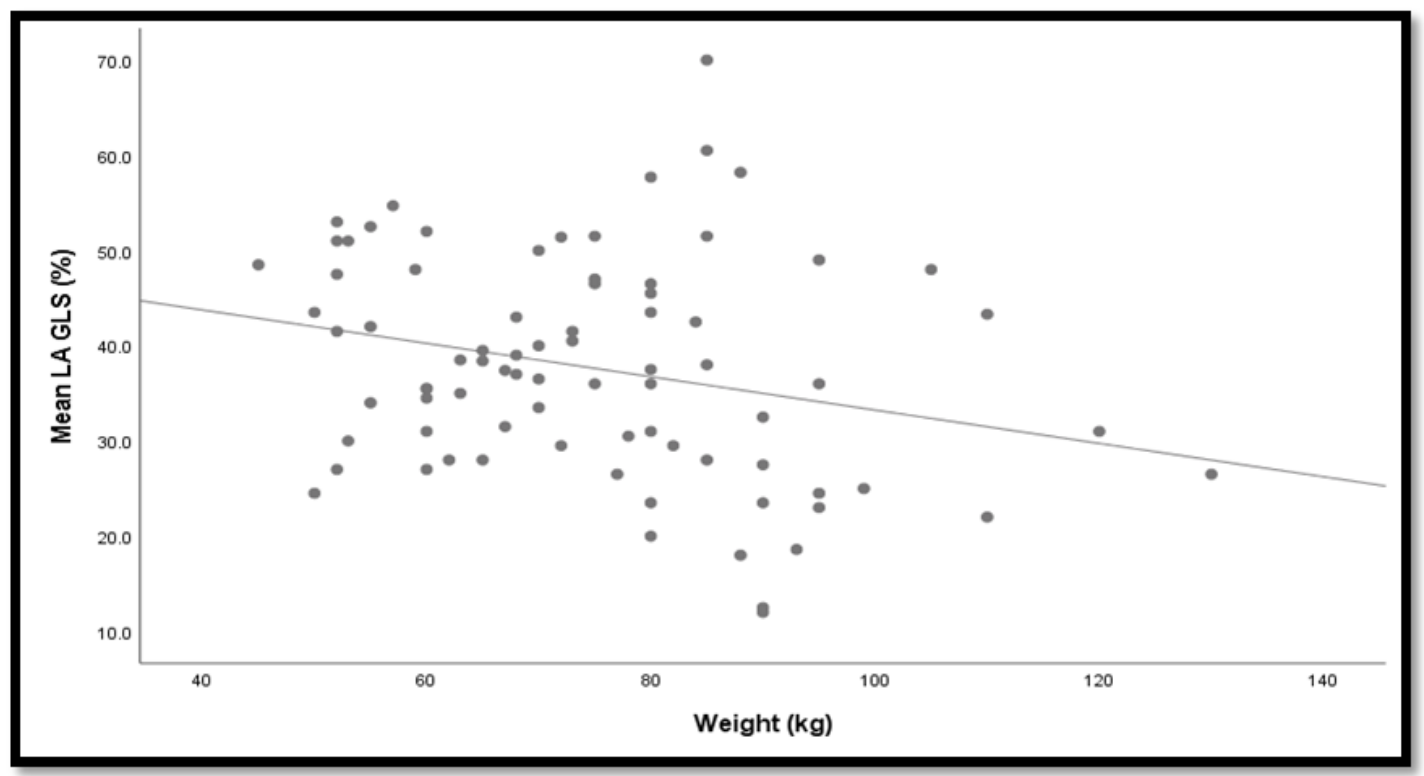

Figure (3): Correlation analysis between mean LA GLS (\%) and weight (kg).

3. Left ventricular posterior wall in diastole (LVPWd): There was a statistically significant negative correlation with the mean LA GLS with $\mathrm{P}$ value $0.002, \mathrm{r}$ value $=-0.343$ (Table 4 and Figure 4).

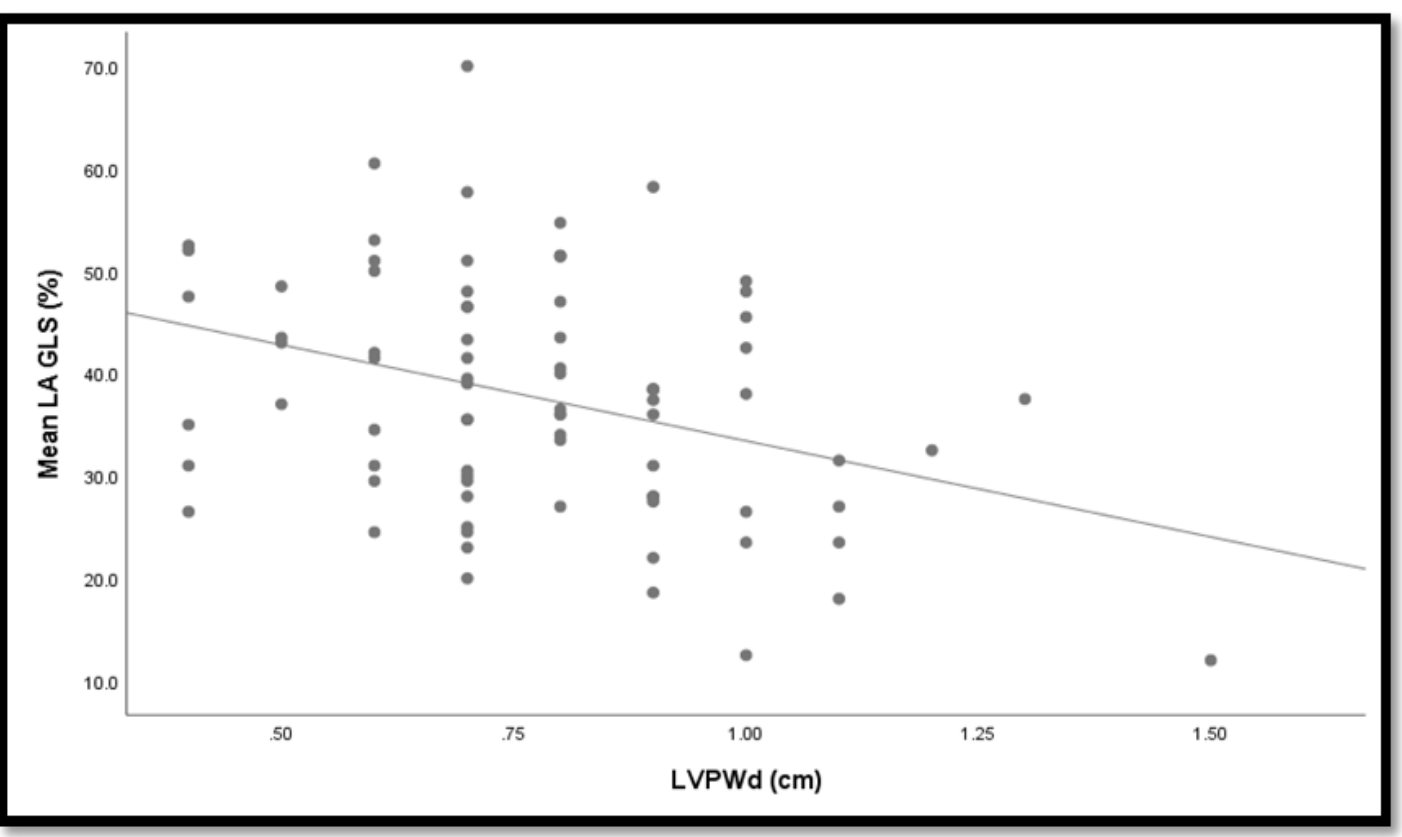

Figure (4): Correlation analysis between mean LA GLS (\%) and LVPWd (cm).

4. Left ventricular end diastolic volume in apical 4 chambers view (LVEDV4C): There was a statistically significant negative correlation with the mean LA GLS with $\mathrm{P}$ value $0.022, \mathrm{r}$ value $=$ 0.256 (Table 4 and figure 5 ). 


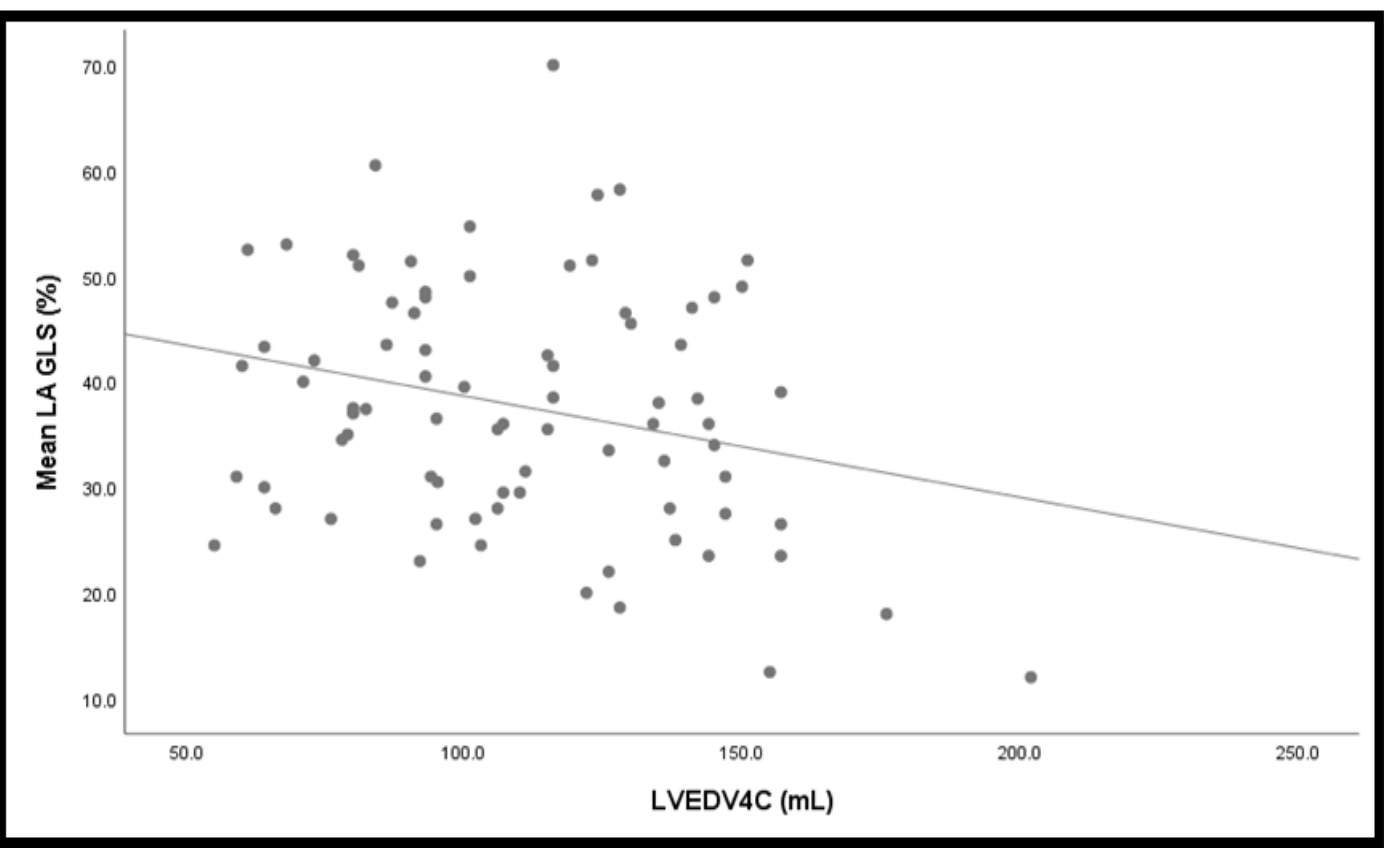

Figure (5): Correlation analysis between mean LA GLS (\%) and LVEDV4C (ml).

5. Left ventricular end systolic volume in apical 4 chambers view (LVESV4C): There was a statistically significant negative correlation with the mean LA GLS with $P$ value 0.021 , $r$ value -0.257 (Table 4 and Figure 6).

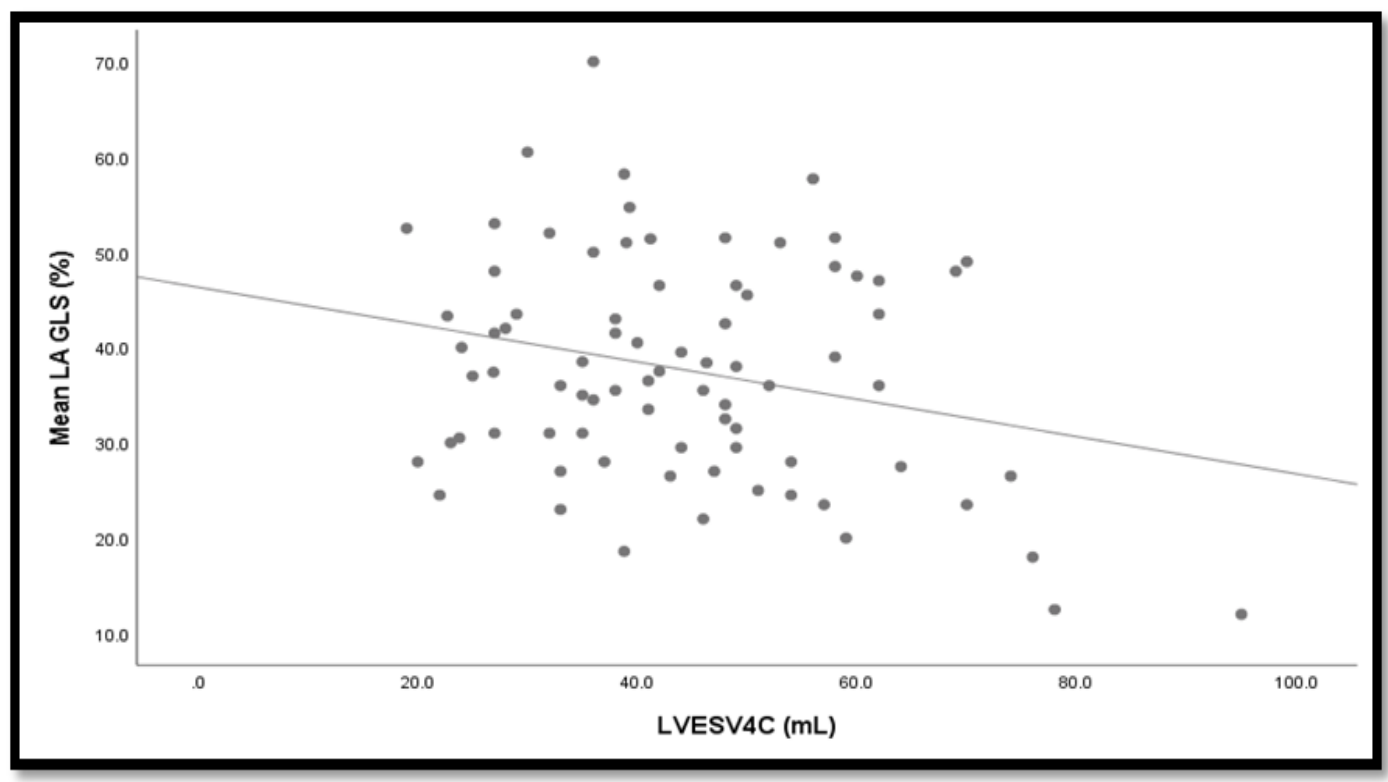

Figure (6): Correlation analysis between mean LA GLS (\%) and LVESV4C (ml).

6. Left atrial diameter (LAD): There was a statistically significant negative correlation with the mean LA GLS with $\mathrm{P}$ value $0.030, \mathrm{r}$ value $=-0.242$

(Table 4 and figure 7). 


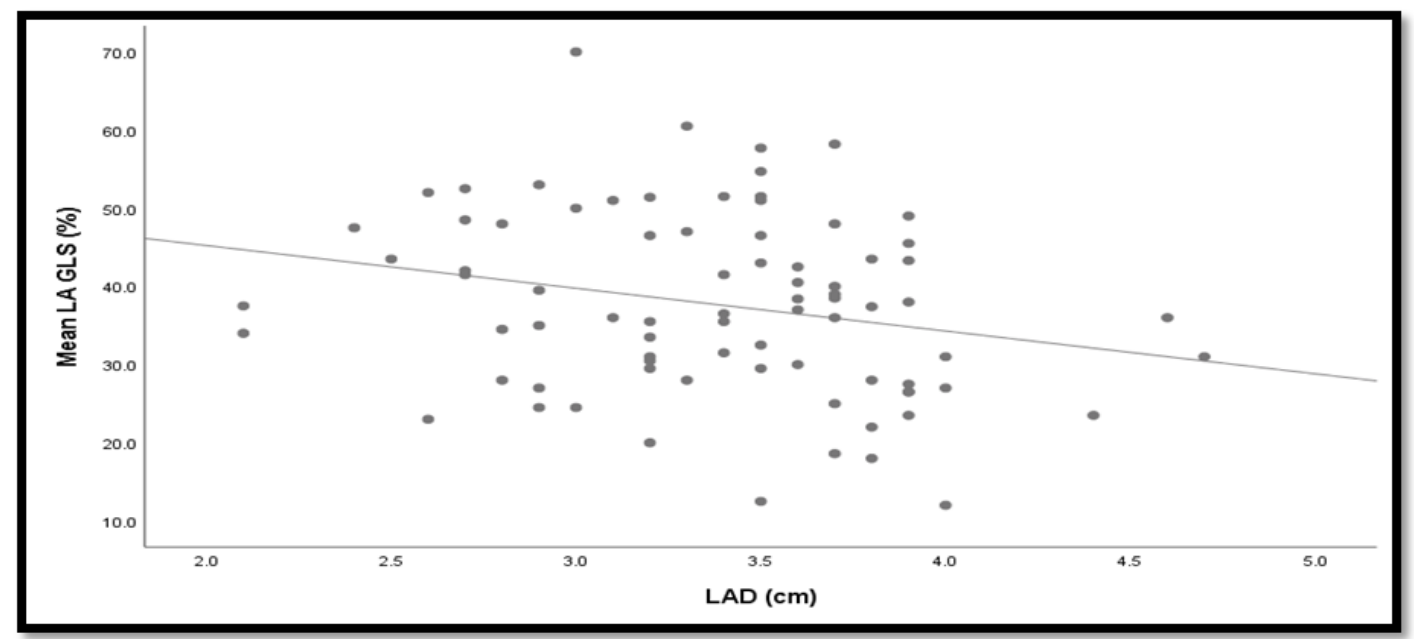

Figure (7): Correlation analysis between mean LA GLS (\%) and LAD (cm).

There was a statistically nonsignificant negative correlation between the mean LA GLS and the Height, LVIDd, LVIDs, IVSd, LVEDV2C, LVESV2C, E/E', Ao, LAV and LAVI with $\mathrm{P}$ value $=0.331,0.067,0.068,0.054$, $0.081,0.259,0.734,0.201,0.078$ and 0.238 respectively and $\mathrm{r}$ value $=-0.110$, $-0.206,-0.205,-0.216,-0.196,-0.128$,
$-0.039, \quad-0.144, \quad-0.198$ and -0.134 respectively (Table 4).

However, regarding the FS and EF, there was a statistically non-significant positive correlation with the mean LA GLS with $\mathrm{P}$ value $=0.470$ and 0.758 respectively and $r$ value $=0.082$ and 0.035 respectively (Table 4).

Table (4): Correlation analysis between mean LA GLS (\%) and other variables

\begin{tabular}{|c|c|c|}
\hline $\begin{array}{ll}\text { Mean LA } \\
\text { GLS (\%) }\end{array}$ & $\mathbf{r}$ & $\mathbf{P}$ \\
\hline Age (years) & -0.412 & $<0.001$ \\
\hline Weight (kg) & -0.260 & 0.020 \\
\hline Height $(\mathrm{cm})$ & -0.110 & 0.331 \\
\hline LVIDd (cm) & -0.206 & 0.067 \\
\hline LVIDs (cm) & -0.205 & 0.068 \\
\hline LVPWd (cm) & -0.343 & 0.002 \\
\hline IVSd (cm) & -0.216 & 0.054 \\
\hline FS (\%) & 0.082 & 0.470 \\
\hline EF (\%) & $\mathbf{0 . 0 3 5}$ & 0.758 \\
\hline LVEDV4C (mL) & -0.256 & 0.022 \\
\hline LVESV4C (mL) & -0.257 & 0.021 \\
\hline LVEDV2C (mL) & -0.196 & 0.081 \\
\hline LVESV2C (mL) & -0.128 & 0.259 \\
\hline $\mathbf{E} / \mathbf{E}^{\prime}$ & -0.039 & 0.734 \\
\hline Ao (cm) & -0.144 & 0.201 \\
\hline LAD (cm) & -0.242 & 0.030 \\
\hline LAV (mL) & -0.198 & 0.078 \\
\hline LAVI (mL/m2) & -0.134 & 0.238 \\
\hline
\end{tabular}




\section{DISCUSSION}

Chronic renal failure leads to structural changes and functional abnormalities in the heart, which are known as uremic cardiomyopathy (Chinnappa et al., 2014). These changes may be progressive and related directly to a grossly aggravated risk of cardiovascular (CV) events and reduced survival rates (McIntyre and Odudu, 2014). Speckle-tracking echocardiography is noninvasive ultrasound imaging technique that allows for an objective and quantitative evaluation of global and regional myocardial function (Yang and Ha, 2015). Previous studies have shown that increased left atrial volume (LAV) as measured by echocardiography is a common finding in end-stage renal disease (ESRD) patients (Tripepi et al., 2007). Therefore, LAV is reported to be a sensitive marker of LV diastolic dysfunction and LA function plays a central role in maintaining optimal cardiac output despite impaired LV relaxation and reduced LV compliance (Hoit, 2014).

In our study, the mean age was $35.3 \pm$ 12.7 years and the difference between the two groups was significant (p value 0.019) this was dis-concordant with (Liu et al., 2014) in which 190 patient underwent noninvasive assessment of left atrial phasic function in patients with hypertension and diabetes using two- dimensional speckle tracking and volumetric parameters and the difference between the studied groups was nonsignificant regarding age.

This discrepancy between the previous study and our results regarding age was due to the difference in mean age (our study mean age was $35.3 \pm 12.7$ years and their study was $51 \pm 11$ years.

In our study, there was a nonsignificant statistical difference regarding gender ( $p$ value 0.891), hypertension and smoking which was concordant with (Baykan et al., 2009) who found that the difference between control group and patients regarding male sex, smoking and hypertension was non- significant and was dis-concordant with (Liu et al., 2014) who found highly significant result this discrepancy between the previous study and our results may be due to presence of diabetes in their risk factors which was excluded in our study.

In our study, LVIDd was the only result among $\mathrm{LV}$ dimensions that was significant; the mean LVIDd of the study population was $4.80 \mathrm{~cm} \pm 0.65 \mathrm{SD}$.

This was concordant with (Hassanin and Alkemary, 2016) who conducted 100 patients on HD and a control group consisted of 40 healthy individuals for Detection of Left Atrium Myopathy, using Two Dimensional Speckle Tracking Echocardiography, found that the difference between the Dialysis Group and Control Group regarding LVEDD was statistically significant ( $\mathrm{p}$ value $<0.001$ ).

In our study, there was non-statistical significant difference regarding LVEF which was dis-concordant with (Hassanin and Alkemary, 2016) who found statistically significant difference this discrepancy between the previous study and our results because Left atrium stiffness was significantly higher in dialysis patients with atrial fibrillation (AF) compared to those without AF and our study excluded AF. 
In our study, there was non-statistically significant difference regarding $\mathrm{LV}$ diastolic function (E/E') which was disconcordant with (Tamulenaite et al., 2018) who studied the changes of left and right ventricle mechanics and function in patients with end-stage renal disease undergoing hemodialysis. They found that hemodialysis patients had significantly higher E/e' ratio and lower E/A ratio compared with the control group this discrepancy between the previous study and our results may be due to presence of diabetes in their risk factors but were excluding diabetic patients and diastolic dysfunction is frequent in patients with type 2 diabetes mellitus and associated with a poor prognosis.

Diastolic function deterioration in type 2 diabetes mellitus was assessed by (Bergerot et al., 2017) who conducted a 3year follow up prospective cohort study on 310 diabetic patients with type 2 DM without overt heart disease and they found that during the 3-year follow-up prevalence of diastolic dysfunction increased from $49 \%$ to $67 \%$.Only $32 \%$ of the patients had a normal diastolic function both at baseline and 3 years and $27 \%$ of the patients presented diastolic function deterioration (Bergerot et al., 2017).

In our study, there was a statistically significant difference regarding Aortic root dimension and there was a statistically significant difference regarding LAV (mL) between hemodialysis group and control group and non- significant difference regarding LAVI $(\mathrm{mL} / \mathrm{m} 2)$ which was dis-concordant with (Tamulenaite et al., 2018) who studied the changes of LA and LV mechanics and function in patients with end-stage renal disease undergoing hemodialysis and found that the LA volume index was significantly higher in the hemodialysis group. This discrepancy between the previous study and our results may be due to presence of diabetes in their risk factors but were excluding diabetic patients and patients with type 2 diabetes mellitus were found to have increased LA volume and impaired atrial compliance and contractility (Atas et al., 2014).

In our study, the left atrial strain (LAGLS) value assessed by speckle tracking echocardiography significantly decreased in patients of group I versus group II with significant value.

This was concordant with (Aksu et al., 2018) who assessed the effect of dialysis type on left atrial function in patients with end stage renal disease. They reported that left atrial peak systolic strain and left atrial strain with contraction were significantly decreased in hemodialysis group compared with the peritoneal dialysis group.

Also concordant with (Altekin et al., 2013) who reported decreased LA strain in ESRD group $(\mathrm{P}<0.0001)$.

\section{CONCLUSION}

The regional function of the left atrial myocardium assessed by two-dimensional speckle tracking echocardiography significantly decreased in renal patients on hemodialysis with preserved left ventricular ejection fraction than normal individuals.

\section{STUDY LIMITATIONS}

The results were obtained from a single medical center, further cohort studies are 
necessary to demonstrate the change of cardiac function from moderate- advanced CKD to ESRD with dialysis therapy and other potential important factors not included in our study such as acid-base and accurate estimation of the volume status pre and post dialysis ... etc. so further studies are required

\section{REFERENCES}

1. Aksu, U., Aksu, D., Gulcu, O., Kalkan, K., Topcu, S., Aksakal, E. and Tanboga, I. H. (2018): The effect of dialysis type on left atrial functions in patients with end- stage renal failure: A propensity score- matched analysis. Echocardiography, 35(3): 308-313.

2. Altekin, R., E., Caglar, B., Karakas, M. S., Ozel, D., Deger, N. and Demir, I. (2014): Evaluation of subclinical left ventricular systolic dysfunction using two-dimensional speckle-tracking echocardiography in patients with non-alcoholic cirrhosis. Hellenic J Cardiol, 55(5): 402-410.

3. Altekin, R., E., Caglar, B., Karakas, M. S., Ozel, D., Deger, N. and Demir, I. (2013): Evaluation of left atrial function using twodimensional speckle tracking echocardiography in end-stage renal disease patients with preserved left ventricular ejection fraction. Kardiol Pol, 71(4): 341-51.

4. American Diabetes Association (2014): Diagnosis and classification of diabetes mellitus. Diabetes care 37.Supplement 1: S81-S90.

5. Baykan, M., Baykan, E. C., Turan, S., Gedikli, Ö., Kaplan, Ş. and Çelik, Ş. (2009): Assessment of left ventricular function and Tei index by tissue Doppler imaging in patients with slow coronary flow. Echocardiography, 26(10), 1167-1172).

6. Bergerot, C., Davidsen, E. S., Amaz, C., Thibault, H., Altman, M., Bellaton, A. and Moulin, P. (2018): Diastolic function deterioration in type 2 diabetes mellitus: predictive factors over a 3-year follow-up. European Heart Journal-Cardiovascular Imaging, 19(1): 67-73.
7. Chinnappa, S., Sandeep S., H., and LipBun, T. (2014): "Is uremic cardiomyopathy a direct consequence of chronic kidney disease?.": 127-130.

8. Dohi, K. (2019): Echocardiographic assessment of cardiac structure and function in chronic renal disease. Journal of echocardiography: 1-8.

9. Geyer, H., Caracciolo, G., Abe, H., Wilansky, S., Carerj, S., Gentile, F. and Sengupta, P. P. (2010): Assessment of myocardial mechanics using speckle tracking echocardiography: fundamentals and clinical applications. Journal of the American Society of Echocardiography, 23(4), 351-369.

10. Götte, M. J., Germans, T., Rüssel, I. K., Zwanenburg, J. J., Marcus, J. T., van Rossum, A. C. and van Veldhuisen, D. J. (2006): Myocardial strain and torsion quantified by cardiovascular magnetic resonance tissue tagging: studies in normal and impaired left ventricular function. Journal of the American College of Cardiology, 48(10), 2002-2011.

11. Hassanin, N., and Alkemary, A. (2016): "Detection of Left Atrium Myopathy Using Two- Dimensional Speckle Tracking Echocardiography in Patients with End- Stage Renal Disease on Dialysis Therapy." Echocardiography 33.2: 233-241.

12. Hoit, B. D. (2014): Left atrial size and function: role in prognosis. Journal of the American College of Cardiology, 63(6): 493505 .

13. Karabuva, S., Carević, V., Radić, M. and Fabijanić, D. (2013): The association of ABO blood groups with extent of coronary atherosclerosis in Croatian patients suffering from chronic coronary artery disease. Biochemia medica: Biochemia medica, 23(3): 351-359.

14. Latif, S. R., Nguyen, V. Q., Peters, D. C., Soufer, A., Henry, M. L., Grunseich, K. and Dicks, D. (2019): Left atrial fibrosis correlates with extent of left ventricular myocardial delayed enhancement and left ventricular strain in hypertrophic cardiomyopathy. The international journal of cardiovascular imaging, 35(7): 1309-1318. 
15. Liu, Y., Wang, K., Su, D., Cong, T., Cheng, Y., Zhang, Y. and Zhong, L. (2014): Noninvasive assessment of left atrial phasic function in patients with hypertension and diabetes using two- dimensional speckle tracking and volumetric parameters. Echocardiography, 31(6): 727-735.

16. McIntyre, C. W. and Odudu, A. (2014, March): Hemodialysis- associated cardiomyopathy; a newly defined disease entity. In Seminars in dialysis, 27(2): 87-97.

17. Meijs, L. P., Bindels, A. J., Bakker, J. and Pinsky, M. R. (2018): Cardiac Function (Cardiac Output and Its Determinants). In Monitoring Tissue Perfusion in Shock: 51-76.

18. Mochizuki, A., Yuda, S., Oi, Y., Kawamukai, M., Nishida, J., Kouzu, H. and Tsuchihashi, K. (2013): Assessment of left atrial deformation and synchrony by three-dimensional speckle-tracking echocardiography: comparative studies in healthy subjects and patients with atrial fibrillation. Journal of the American Society of Echocardiography, 26(2): 165-174.
19. Tamulènaitė, E., Žvirblytė, R., Ereminienè, R., Žiginskienè, E. and Ereminienè, E. (2018): Changes of left and right ventricle mechanics and function in patients with end-stage renal disease undergoing haemodialysis. Medicina, 54(5): 87.

20. Thomas, L., Marwick, T. H., Popescu, B. A., Donal, E. and Badano, L. P. (2019): Left atrial structure and function, and left ventricular diastolic dysfunction: JACC stateof-the-art review. Journal of the American College of Cardiology, 73(15): 1961-1977.

21. Tripepi, G., Benedetto, F. A., Mallamaci, F., Tripepi, R., Malatino, L. and Zoccali, C. (2007):Left atrial volume monitoring and cardiovascular risk in patients with end-stage renal disease: a prospective cohort study. Journal of the American Society of .1322-1316 :)4(18,Nephrology

22. Yang, W. I., and Ha, J. W. (2015): Noninvasive assessment of vascular alteration using ultrasound. Journal of clinical hypertension: 21-25. 


\section{تقييم وظيفة الأذين الأيسر باستخدام التتبع التقطي على عضلة

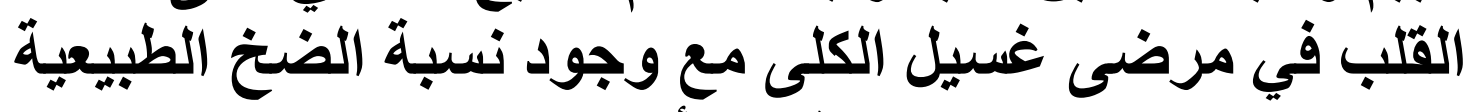 للبطين الأيسر}

أحمد علي كحيل، أحمد محمد صلاح الدين أحمد، سامح رفت حسن علام

قسم أمراض القلب والأوعية الدموية، كلية الطب، جامعة الأزهر

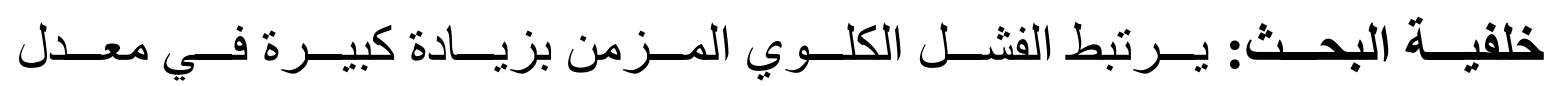

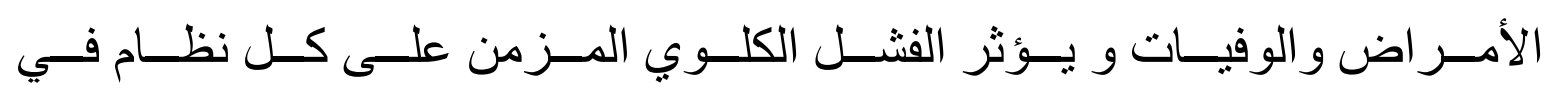

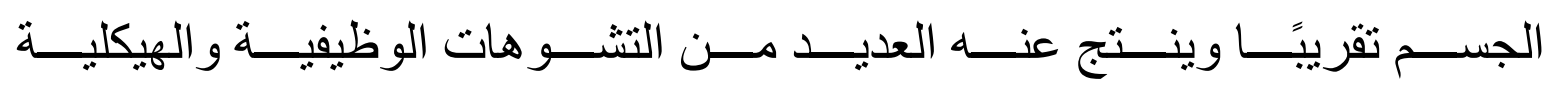

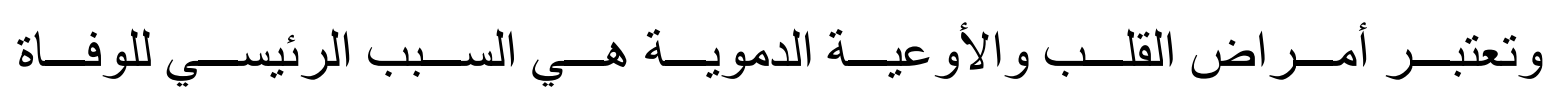

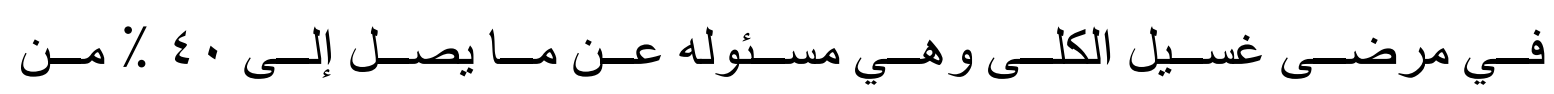

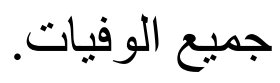

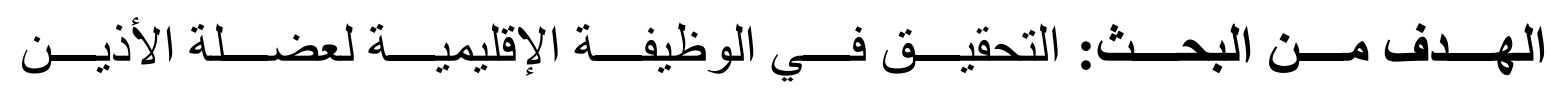

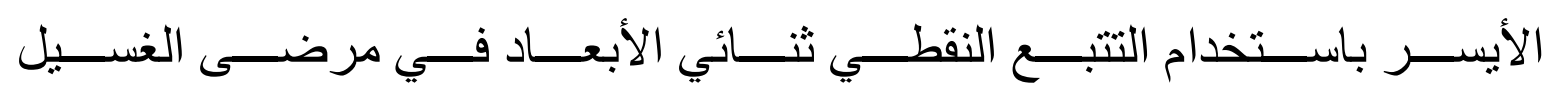
الكلوى مع وجود نسبة الضخ الطبيعيه للبطين الأيسر.

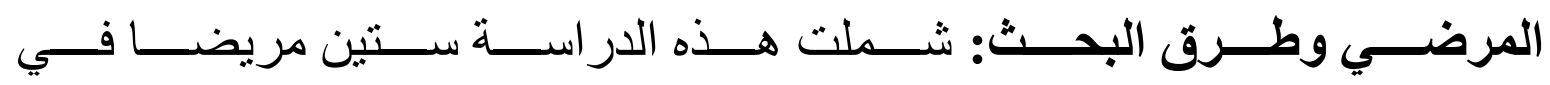

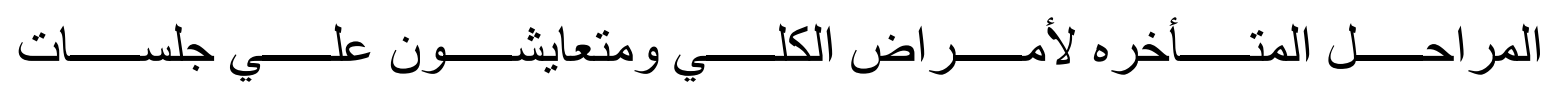

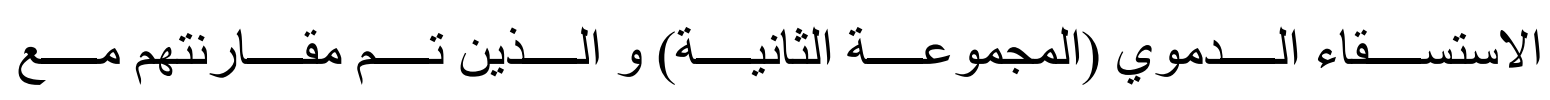

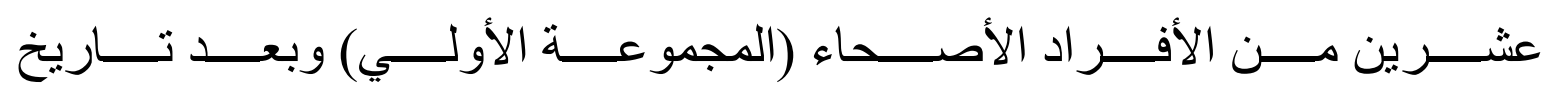

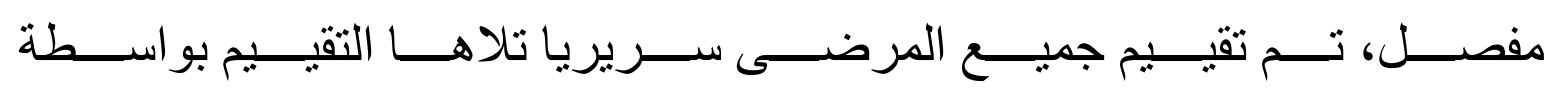

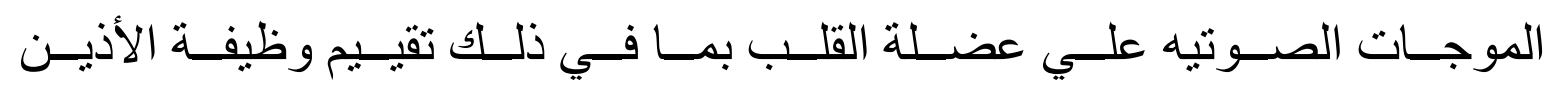
الأيسر بو اسطة التتبع النقطي لعضلة القلب. 


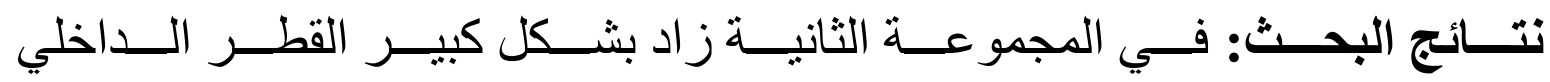

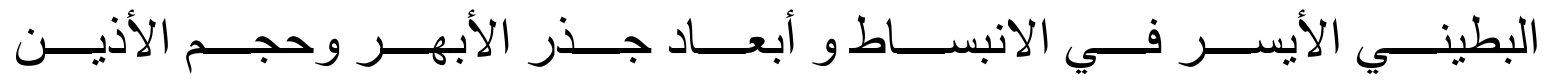

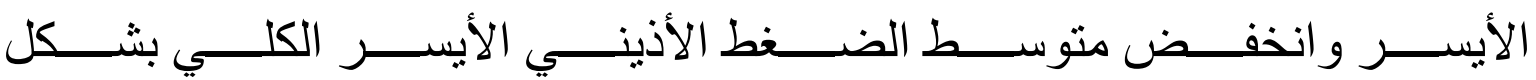

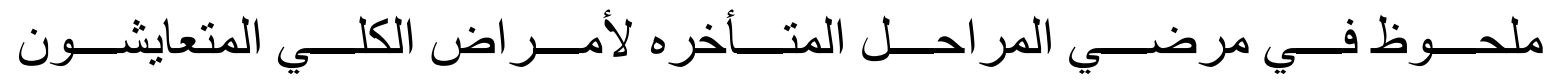
علي جلسات الاستسقاء الدموي.

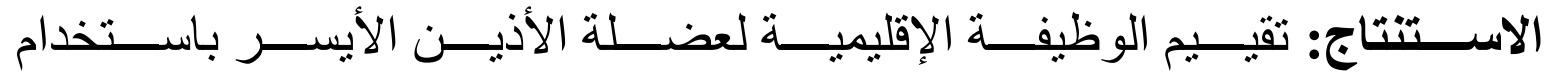

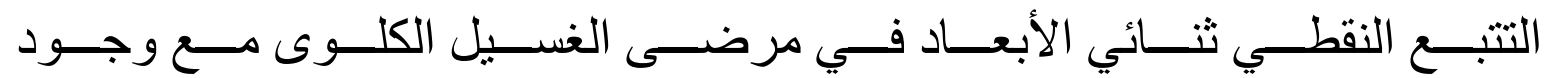

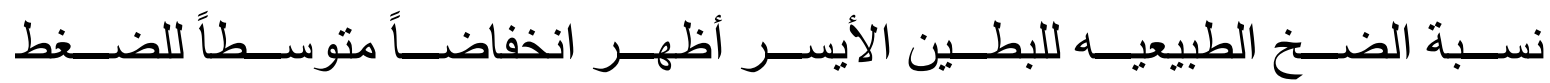

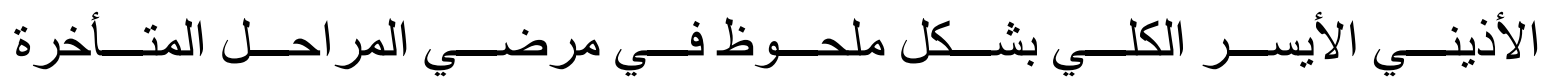
لأمر اض الكلي المتعايثين علي جلسات الاستسقاء الدموي. 